\title{
Higher glutathione peroxidase (GPx) activity in physically-active adolescent females in comparison with healthy sedentary controls
}

\author{
E. Alshammari ${ }^{1}$, J. A. Nurmi-Lawton ${ }^{1}$, S. Shafi ${ }^{1}$, S. A. Lanham-New ${ }^{1}$ and G. A. A. Ferns ${ }^{2}$ \\ ${ }^{1}$ Faculty of Health and Medical Sciences, University of Surrey, Guildford, GU2 7XH, Surrey, UK and ${ }^{2}$ Post Graduate \\ Medical School, University of Surrey, Guildford, GU2 7XH, Surrey, UK
}

Reactive oxygen species (ROS) have been associated with several degenerative conditions including: CVD, cancer, diabetes and cataracts $^{(1,2,3)}$. There is a growing body of evidence that antioxidants also play a role in bone health, including osteoporosis ${ }^{(4)}$. Antioxidants may reduce the damaging effects of ROS by converting them into less-harmful species. Production of ROS from osteoclasts is a normal physiological function, which may alter the rate of bone remodelling when associated with other risk factors ${ }^{(5)}$. Recent studies have suggested that GPx activity may be significantly increased through exercise ${ }^{(6)}$.

The aim of the present study was to assess the levels of serum GPx activity in active and inactive adolescent girls and to determine the effects of age, BMI and dietary intake on GPx. A further aim was to investigate whether there is an association between GPx and bone health. The subjects were participants in a 3-year longitudinal investigation of exercise and peak bone mass (PBM) development. Seventyeight healthy subjects comprising thirty-eight competitive gymnasts and forty healthy sedentary adolescent females (age 8-17 years) were recruited as described previously ${ }^{(7)}$. GPx was measured using GPx assay kit (Cayman Chemical; Immunodiagnostic Systems Limited Ltd, Boldon, Tyne \& Wear, UK).

The results showed that serum GPx activity was significantly higher in healthy competitive gymnasts $(n$ 38) compared with the healthy sedentary adolescent females ( $n$ 40). Data for bone mineral density (BMD), dietary intakes and anthropometric measurements in female gymnasts are shown in the Table. The relationship between serum GPx and BMD, broadband ultrasound attenuation (BUA) of the right and left feet, lumbar spine L2-L4 BMD, lumbar spine L2-L4 bone mineral content (BMC), total body BMC, weight, height and BMI, in female gymnasts indicated no significant correlation.

\begin{tabular}{|c|c|c|c|c|c|c|c|c|c|}
\hline & $\begin{array}{c}\text { Serum GPx } \\
(\mathrm{nmol})\end{array}$ & $\begin{array}{c}\text { Total body } \\
\text { BMD }\end{array}$ & $\begin{array}{l}\text { Weight } \\
(\mathrm{kg})\end{array}$ & $\begin{array}{l}\text { Height } \\
\text { (m) }\end{array}$ & $\begin{array}{c}\mathrm{BMI} \\
\left(\mathrm{kg} / \mathrm{m}^{2}\right)\end{array}$ & $\begin{array}{c}\text { Protein } \\
(\mathrm{g} / \mathrm{d})\end{array}$ & $\begin{array}{l}\text { Fat } \\
(\mathrm{g} / \mathrm{d})\end{array}$ & $\begin{array}{l}\mathrm{CHO} \\
(\mathrm{g} / \mathrm{d})\end{array}$ & $\begin{array}{l}\text { Fibre } \\
(\mathrm{g} / \mathrm{d})\end{array}$ \\
\hline \multicolumn{10}{|c|}{ Gymnasts (n 38): } \\
\hline Mean & $157^{*}$ & 0.946 & $31.7^{*}$ & $1.36^{*}$ & $16.8^{*}$ & 55.6 & $67.8^{*}$ & 230 & 10.1 \\
\hline $\mathrm{SE}$ & 11.1 & 0.014 & 1.3 & 0.016 & 0.29 & 1.95 & 2.89 & 8.66 & 0.51 \\
\hline \multicolumn{10}{|c|}{ Controls ( $n$ 40): } \\
\hline Mean & 126 & 0.947 & 41.0 & 1.47 & 18.5 & 58.0 & 74.3 & 245 & 10.7 \\
\hline $\mathrm{SE}$ & 8.8 & 0.014 & 1.5 & 0.018 & 0.41 & 1.39 & 1.71 & 6.63 & 0.35 \\
\hline
\end{tabular}

These findings indicate that serum GPx is higher in gymnasts, and would suggest that regular intense exercise may enhance antioxidant status. This outcome in turn may help to protect against degenerative diseases and preserve bone health by preventing free radical-induced bone resorption. Further analysis of the effect of GPx activity and trace elements status on bone turnover in this population group is currently underway.

E. A. is recipient of a PhD scholarship funded by the Saudi Arabian Government. Funding from the National Osteoporosis Society is gratefully acknowledged.

1. Kumar V et al. (1991) Eur Heart J 12, Suppl. D, 163-165.

2. Witz G (1991) Proc Soc Exp Biol Med 198, 675-682.

3. Opara EC (1998) Expert Opin Investig Drugs 7, 785-795.

4. Zhang J et al. (2006) Am J Epidemiol 163, 9-17.

5. Sheweita SA et al. (2007) Curr Drug Metab 8, 519-525.

6. Gonenc S et al. (2000) Indian J Physiol Pharmacol 44, 340-344.

7. Nurmi-Lawton JA et al. (2004) J Bone Miner Res 19, 314-322. 